\title{
UM OLHAR SOBRE A INCLUSÃO DAS MULHERES NO CURSO DE AGROPECUÁRIA: UM ESTUDO ESPECÍFICO EM UM CAMPUS DO INSTITUTO FEDERAL FARROUPILHA
}

\author{
Gisiê Mello Balsamo iD1 e Catiane Mazocco Paniz iD2
}

\section{Resumo}

O presente artigo é fruto de uma pesquisa de mestrado do curso de Educação Profissional e Tecnológica do Instituto Federal Farroupilha (IFFar) - campus Jaguari. Tendo em vista o discurso machista e preconceituoso referente às mulheres no decorrer da história e a consequente construção da desigualdade de gênero, estabeleceu-se culturalmente o curso de agropecuária como masculino. Assim, este trabalho desenvolveu-se a partir de uma pesquisa qualitativa do tipo estudo de caso e teve como instrumento para a coleta de dados questionários semiabertos e a consulta de documentos da Instituição. Os questionários foram enviados por e-mail para as alunas dos segundos e terceiros anos, ex-alunas e professoras do curso de agropecuária do Ensino Médio Integrado do campus " $A$ " do IFFar. O objetivo foi compreender como elas vêm vivenciando esta experiência dentro de um curso considerado socialmente para homens. A análise dos dados foi realizada a partir da Análise Textual do Discurso (ATD). Com a pesquisa concluiu-se que apesar do aumento do número de mulheres matriculadas no curso e das políticas públicas em favor delas, ainda existe o preconceito de gênero na agropecuária. Acredita-se que ainda há a necessidade de reflexão acerca do assunto e a consequente desnaturalização de conceitos e costumes ainda hoje enraizados na sociedade.

Palavras-chave: Agropecuária. Mulheres. Preconceito.

\section{A LOOK AT THE INCLUSION OF WOMEN IN THE AGROPECUARIA COURSE: A SPECIFIC STUDY IN A CAMPUS OF THE FEDERAL FARROUPILHA INSTITUTE}

\section{Abstract}

This work presents results of a master's research on Professional and Technological Education Graduate Program at the Federal Farroupilha Institute (IFFar - Instituto Federal Farroupilha, in Portuguese) - Jaguari campus. Considering the sexist and gender bias discourse regarding women throughout history and the following gender inequality, the agriculture courses were culturally established having a masculine character. With this motivation, this work was developed from a qualitative approach of case study type, having the semi-open questionnaires and the consultation of documents of the Institution as the tools for the data collection. The questionnaires were sent by e-mail to the female students of the second and third years, former female students and female teachers of the integrated high school agriculture course on campus " $A$ " at IFFar. The main objective was to understand how they have been 
experiencing to be into a course socially considered for men. The data analysis was performed using the Textual Discourse Analysis (ATD - Análise Textual do Discurso, in Portuguese). The present research concluded that despite the increase in the number of women enrolled in the considered course and the public policy in favor of them, there is still gender bias in the agriculture field. It is believed that there is still a need for reflection on the subject and the consequent denaturalization of concepts and morals that are still rooted in society nowadays.

Keywords: Agriculture. Women. Gender bias.

\section{Introdução}

Trago esta pesquisa enfatizando a construção histórica patriarcal e machista a qual estabeleceu papéis sociais para homens e mulheres desempenharem socialmente, delimitando, a partir da variável sexo biológico, como se deve ser e agir na sociedade. A partir destas crenças, o curso de agropecuária desenvolveu-se como sendo uma atividade específica para homens, uma vez que estes se utilizam, na maioria das vezes, da força física nas atividades laborais. Lembrando que esta condição (força física) não era considerada característica das mulheres.

Aos poucos, a partir de lutas sociais em busca de direitos, as mulheres foram se empoderando e consequentemente ocupando mais estes espaços sociais delimitados culturalmente como para homens. Como reflexo desta luta social e do aumento delas na área da educação, o curso de agropecuária começou a receber mais mulheres em sala de aula. Em conjunto com este progresso houve o aumento do comportamento machista e preconceituoso em relação a elas, dentro e fora das Instituições de ensino.

Tendo em vista esta sociedade machista, produzi este artigo como resultado da minha pesquisa de mestrado. Esta foi desenvolvida no curso de Agropecuária do Ensino Médio Integrado da Educação Profissional e Tecnológico do campus " $A$ "1 do Instituto Federal Farroupilha (IFFar).

O objetivo da pesquisa foi investigar como as mulheres (alunas, ex-alunas e professoras) vêm vivenciando esta experiência dentro do curso de agropecuária. Para isto, procurei saber, através de um questionário, se há preconceito e machismo em relação à presença delas nas atividades agropecuárias desenvolvidas no campus e fora dele.

A partir da coleta de dados, da análise e do embasamento teórico, confirmei a hipótese inicial de que, apesar do aumento das mulheres no curso de agropecuária e da constante luta por direitos, ainda há o preconceito e o discurso machista direcionado a elas. No decorrer do texto trago o resultado deste trabalho a partir de uma discussão teórica, da explanação dos dados coletados e da análise realizada após as coletas.

\section{A construção histórica do papel social das mulheres}

Historicamente a sociedade estabeleceu preceitos e privilégios do sexo masculino em relação ao feminino, definindo, a partir de diferenças sexuais

${ }^{1}$ A fim de não identificar o campus no qual foi realizada a pesquisa o chamarei de campus " $\mathrm{A}$ ". 
biológicas, papéis sociais "adequados" para homens e mulheres desempenharem socialmente. Estamos no século XXI e ainda sofremos reflexos desta sociedade patriarcal, seja através da violência contra as mulheres, de salários inferiores aos dos homens ou da cobrança social para desempenharem um papel social de boa mãe, esposa e dona de casa.

As profissões e cursos acadêmicos, como consequência desta construção histórica, ainda são vistos a partir do binarismo masculino/feminino. Sendo assim, as mulheres permanecem atreladas a profissões ligadas ao cuidado do outro, como na pedagogia, enfermagem e serviço social, enquanto do homem se espera, socialmente, seguirem para as áreas rurais e exatas.

Com o objetivo de iniciar a discussão teórica em relação ao tema, apresento Thomas Laqueur (2001), historiador e sexólogo, o qual relata que até o século XVIII o modelo científico dominante que existia em relação ao sexo biológico era o de que homens e mulheres possuíam a mesma genitália. A partir disto a diferença entre as pessoas estava no fato de que a genitália das mulheres ficava para dentro do corpo, enquanto a dos homens para fora. No século II d.c., por exemplo, Galeno desenvolveu o modelo de identidade estrutural dos homens e das mulheres. Para ele, o que faltava nas mulheres era um calor vital, fato este que justificava seus órgãos sexuais serem internos. Esta era considerada um homem imperfeito a quem faltava a força e o calor vital. "Embora sejam de sexos diferentes, em conjunto são o mesmo que nós, pois os que estudaram com mais afinco sabem que mulheres são homens viradas para dentro" (LAQUEUR, 2011, p. 16).

No séc. XVIII ocorreu na Europa o movimento filosófico e intelectual chamado Iluminismo, o qual defendia o uso da razão e o avanço da ciência. Laqueur (2011) traz que neste período começou a ser defendido pelos cientistas, através de questões biológicas constatáveis, que não existia somente um sexo, mas sim, dois.

No entanto, quando começou a ser defendido as diferenças corporais entre homens e mulheres estes já estavam marcados por representações de poder pois, a mulher já era considerada um homem imperfeito e inferior socialmente. Homens e mulheres deveriam seguir um tipo de conduta social e emocional adequadas a natureza biológica do "seu sexo". Aqueles que não seguiam as normas sociais eram considerados indivíduos desviantes, anormais e doentes.

Conforme a professora e pesquisadora, Ana Maria Colling (2015), a imagem das mulheres que se construiu ao longo da história é o de uma pessoa responsável pela maternidade, pelo casamento e o cuidado do lar. Enquanto ser homem significa a participação no mercado de trabalho, a força e o espírito de aventura. As crianças, por exemplo, ainda são ensinadas a desempenhar papeis sociais de acordo com seu gênero, sendo as meninas educadas para serem boa mãe e dona de casa exemplar, enquanto os meninos devem prover a família, brincar de carrinhos e bonecos.

Na Idade Média a Igreja Católica foi a responsável pela educação das pessoas e, portanto, também contribuiu para disseminar a cultura patriarcal nas sociedades. Jane Soares Almeida (2007) relata que nessa época as mulheres deveriam ser preparadas para o casamento e a maternidade, representando a pureza e a castidade, formas estas pela qual poderiam atingir a salvação divina. Aquelas desviantes dos padrões religiosos eram vistas como alguém que ameaçava o equilíbrio da família e da sociedade.

Conforme Guacira Louro (2008), o casamento e a maternidade eram considerados tarefas femininas e qualquer atividade profissional era considerada 
como um desvio dessas funções sociais. Assim, o magistério, por exemplo, adquiriu características tradicionalmente associados às mulheres, como 0 amor, $a$ sensibilidade e o cuidado. Atualmente muitas profissões que estão ligadas a estes atributos ainda são consideras como adequadas para as mulheres.

A época do movimento Iluminista e da Revolução Francesa, também foi palco da luta das mulheres por direitos políticos e sociais iguais aos dos homens. Já a luta feminista contemporânea veio com a busca da libertação das mulheres ao estigma de inferioridade a partir de gênero, independente de classe social, cultural e econômica. Aos poucos, a partir da busca por direitos, as mulheres foram ganhando espaço na sociedade.

É importante ressaltar que o movimento político chamado Feminismo surgiu e ressurgiu como referência a cada momento histórico que se sobressaiu na sociedade. Segundo Jacilene Silva (2019), cada época se lutou por demandas diferentes, as quais sempre buscaram alcançar e defender direitos das mulheres. Houveram lutas para reivindicar direitos civis básicos, como participar da vida pública, ter direito ao voto, ser votada, administrar bens e fortunas, assim como também, terminar com o ideal de mulher que era ser uma boa dona de casa e mãe. Não servia mais a elas o papel de mulher universal e indiscriminado, era hora de se buscar o reconhecimento das diversas identidades femininas.

Foi a partir das diferenças sexuais e dos padrões esperados para que homens e mulheres desempenhassem na sociedade, que se tornou necessário diferenciar sexo de gênero. Gisele Gomes (2011) traz que na sociologia a denominação sexo significa as partes anatômicas e fisiológicas que definem o corpo do homem e da mulher, enquanto gênero são as diferenças psicológicas, culturais e sociais das pessoas, ou seja, aquilo que a cultura traz como socialmente adequado para mulheres e homens desempenharem.

O termo gênero, segundo a historiadora Joan Scott (1995) surgiu entre as feministas americanas na década de 1980. Neste período as mulheres questionavam - caráter social dado as diferenças baseadas no sexo das pessoas. A palavra apresentava a rejeição ao determinismo biológico implícito nas palavras "sexo" ou "diferença sexual" utilizado na sociedade.

Conforme Louro (2008), estes papéis sociais que delimitam a homens e mulheres, são comportamentos padronizados que uma sociedade estabelece para as pessoas desempenharem, ou seja, as roupas, o modo de se relacionar ou de agir conforme o seu sexo biológico. Isto acaba por delimitar e padronizar a maneira de ser mulher e ser homem, anulando, consequentemente, a identidade de cada um.

Louro (2008) afirma que não deve ser as características sexuais que determinem a alguém ser feminino ou masculino, mas sim, a forma como essas características são representadas em uma dada sociedade e momento histórico. Sendo assim, gênero passa a ser uma construção em um dado momento histórico e social, abrindo, portanto, a possibilidade de se incluir as várias representações de mulheres e homens.

Esse pensamento dicotômico e polarizado de forma rígida e imutável sobre o gênero feminino e masculino estabelecido nas sociedades, segundo Louro (2008), precisa ser desconstruído e desnaturalizado. Atualmente ainda se entende homens e mulheres em dois polos opostos e dentro de uma relação invariável de dominação e submissão do primeiro em relação ao segundo. É imprescindível que as pessoas aceitem a pluralidade de formas de ser do ser humano, as diversas formas de 
masculinidade e feminilidade que possa existir, assim como também, acabem com a hierarquia estabelecida entre os mesmos.

Um longo processo de lutas por mudanças nos padrões culturais de gênero proporcionou, nas últimas três décadas, segundo Silva (2019), que diminuísse as tradicionais barreiras à entrada das mulheres no mercado de trabalho e em meios sociais antes considerados "para homens". Estas lutas também possibilitaram maior igualdade de direitos entre homens e mulheres e o crescente empoderamento feminino.

Em concordância com o pensamento de igualdade de direitos e gênero, o Brasil em 1988 acrescentou o Art.50, I, CF/88 "Homens e mulheres são iguais em direitos e obrigações, nos termos desta Constituição"; neste todas as pessoas, independentemente de seu gênero, são iguais sob a ótica da Constituição Federal do Brasil. Isso quer dizer que todas e todos devem ter os mesmos direitos, oportunidades, responsabilidades e obrigações. Devido à importância deste inciso ele é considerado um direito indispensável à cidadania, à sociedade e ao Estado brasileiro.

Ressalta-se que essa igualdade de gênero não significa ignorar a existência de diferenças entre homens e mulheres, mas sim afirmar que o gênero não deve ser um critério de discriminação negativa e nem a causa para que se reconheça à uma pessoa menos direito ou mais obrigações.

Seguindo o mesmo compromisso de erradicação do preconceito e do machismo, os Institutos Federais, inclusive no campus " $A$ ", apresentam programas de incentivo e valorização das mulheres. A Coordenação de Assistência Estudantil CAE e o Núcleo de Gênero e Diversidade e Sexual - NUGEDIS promovem reflexões sobre o protagonismo das mulheres na sociedade, o empoderamento feminino e a diversidade de gênero. Através dos profissionais que atuam no Núcleo é possível promover a desnaturalização de discursos, garantir o acesso, a permanência e a formação qualificada dos discentes frequentadores da Instituição, independentemente de cor, raça e gênero.

\section{Metodologia}

O presente artigo é resultado de uma pesquisa qualitativa realizada na área educacional no ano de 2019 e desenvolvida no campus "A" do Instituto Federal Farroupilha, a partir de um estudo de caso.

A coleta de dados, inicialmente, foi uma análise documental do histórico de mulheres matriculadas no curso de Agropecuária da Instituição em um tempo de 10 anos. Conforme Antônio Carlos Gil (2008) a coleta de dados através de documentos permite o conhecimento histórico da Instituição e proporciona um conhecimento mais objetivo da realidade temporal. Em um segundo momento realizei um levantamento bibliográfico em relação ao tema.

Por último, mas não menos importante, realizei a coleta dos dados a partir de um questionário semiaberto, o qual foi enviado por e-mail às participantes. No que se refere aos sujeitos da pesquisa optei pelas estudantes do segundo e terceiro ano, professoras e ex-alunas do curso de Agropecuária do campus " $A$ ". Minha escolha por realizar a pesquisa com as alunas de segundo e terceiro ano, assim como as exalunas, se deu porque estas já frequentaram ao menos um ano de curso e já vivenciaram experiências positivas ou negativas em relação a suas presenças na 
agropecuária. Quanto as professoras, também optei somente as do gênero feminino, para visualizar o que elas sentem enquanto mulheres nesta área de ensino.

Tendo em vista o estigma dos cursos e a violência de gênero ainda presente nas sociedades, elaborei as questões tendo como objetivo conhecer as experiências e sentimentos vivenciados pelas mulheres que estão relacionadas ao curso de Agropecuária do campus " $A$ ". Um ponto importante que levei em consideração ao escolher a aplicação do questionário foi, o que segundo Gil (2008) afirma, o fato deste recurso permitir o anonimato das respostas. Como não houve o meu contato direto com as participantes, isso permitiu que elas se sentissem mais à vontade na hora de exporem suas ideias.

Inicialmente, via e-mail, realizei o convite, a explicação e a importância social da pesquisa. Após obter a resposta das mulheres que gostariam de colaborar com o trabalho, enviei o questionário. Nove professoras se disponibilizaram a participar, no entanto, somente três retornaram a pesquisa. Além das professoras que atuam em sala de aula, recebi também o questionário da profissional responsável, no momento da coleta, pelo NUGEDIS do campus " $A$ ".

No que se refere às discentes do segundo e terceiro ano do curso, cento e cinco aceitaram participar, no entanto retornou apenas vinte e sete questionários. Em relação às ex-alunas, mandei dezesseis questionários, retornando apenas oito. No total contabilizei trinta e nove questionários para a análise.

Quanto a análise dos dados utilizei os pressupostos da Análise Textual Discursiva (ATD), a qual me permitiu chegar a uma conclusão referente ao objetivo proposto inicialmente. A ATD, segundo Moraes e Galiazzi (2006), apresenta quatro elementos a serem seguidos durante a análise: desconstrução e unitarização, categorização e metatexto.

A partir dos processos anteriores, obtive uma compreensão do tema pesquisado e a construção do metatexto. Conforme Moraes; Galiazzi (2006) esse momento é uma ponte entre as categorias estabelecidas através da reflexão sobre as informações e a construção de uma tese referente à compreensão final.

Como resultado da análise, estabeleci duas categorias emergentes: Limites e Possibilidades. A primeira categoria traz a discussão em relação a percepção das mulheres frente aos obstáculos encontrados por elas no curso de Agropecuária do campus " $A$ ". Enquanto a segunda categoria é uma reflexão delas frente as mudanças de crenças e comportamentos em relação ao preconceito de gênero.

$\mathrm{O}$ instrumento de coleta, assim como o projeto de pesquisa, foi submetido e aprovado pelo Comitê de Ética em Pesquisa com Seres Humanos do Instituto Federal Farroupilha sob o número de registro Caae 11600119.2.0000.5574. Esta foi realizada mediante a assinatura do Termo de Consentimento Livre e Esclarecido (TCLE) disposto aos maiores de dezoito anos, assim como aos responsáveis pelas menores de idade. O Termo de Assentimento (TA) foi disponibilizado para as alunas menores de dezoito anos.

\section{Resultados e discussões}

No sentido de contemplar os objetivos da pesquisa, apresento em seguida os resultados e a discussão dos dados, a partir das duas categorias emergentes: Os limites e As possibilidades. 


\subsection{Os limites}

O comportamento machista em relação a presença das mulheres no curso de Agropecuária caracteriza uma barreira, muitas vezes invisível, vivenciada por alunas e professoras. A partir disto, esta categoria tem como objetivo trazer as dificuldades encontradas por elas no curso de Agropecuária do campus "A".

Inicialmente, a partir da análise documental da Instituição, verifiquei que o número de alunas matriculadas no curso no ano de 2009 era mínimo em relação a quantia de meninos inscritos. Isto porque os cursos ligados às áreas rurais, no geral, carregam, de forma mais acentuada, o estigma de serem somente para homens.

Percebi, através da análise, que gradualmente esta diferença foi diminuindo, porém, isto será discutido na segunda categoria.

\section{Figura 1: Número de mulheres e homens matriculados no curso Integrado em Agropecuária no decorrer de 10 anos no campus "A"}

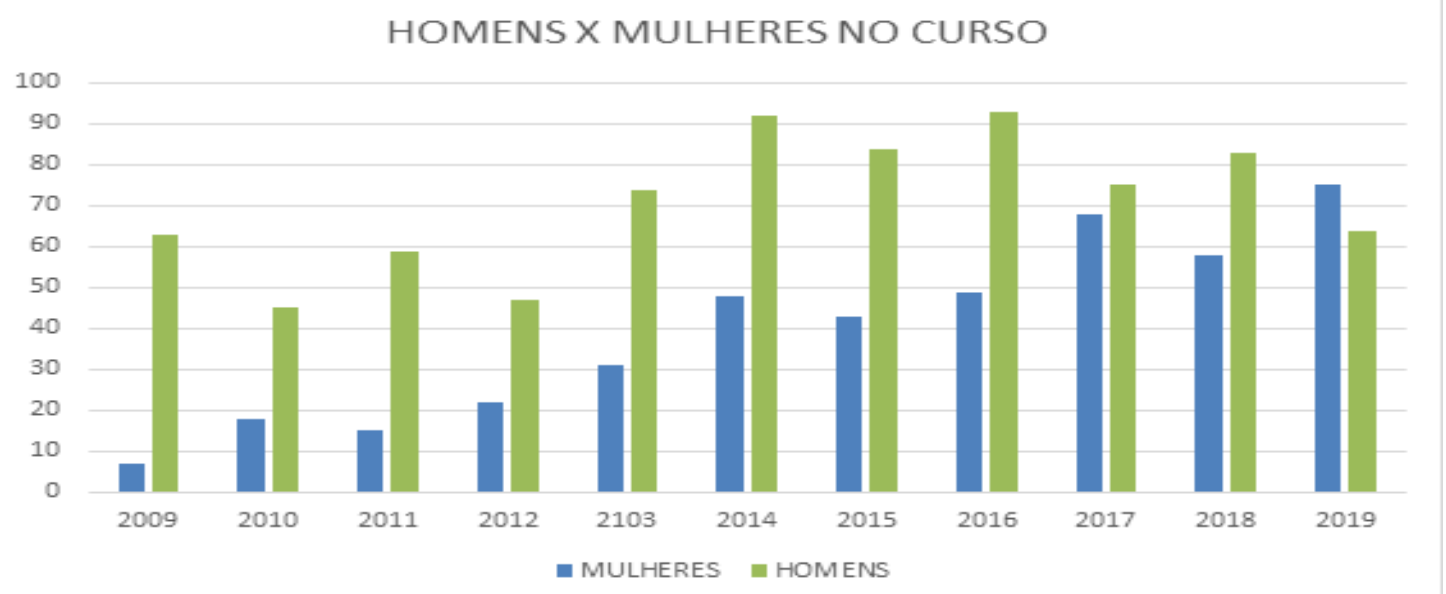

Fonte: Elaboração do autor a partir dos documentos da Instituição (2019).

Referente ao pequeno número de alunas no curso de agropecuária, na década de 1990, temos o relato da professora P.A. que traz a realidade durante a sua formação, momento este em que o número de mulheres no curso era mínimo em relação a quantia de homens:

Cursei Engenharia Agronômica na década de 1990 na UFSM. Na turma de 60 estudantes éramos três mulheres. Portanto, $10 \%$ do total de 650 estudantes do curso. No grupo de professores tínhamos somente duas professoras. O preconceito sempre esteve presente durante a formação acadêmica e continuou na atuação profissional. (P.A. - Professora).

Saliento que mesmo havendo o aumento do número de mulheres matriculadas no curso, ainda assim, permanecem crenças machistas frente a formação delas na área rural. "Acho que por mais que as mulheres venham tomando seu lugar nos cursos de ciências rurais, o preconceito ainda é muito grande" (L.F. - aluna).

Ao analisar os dados contabilizei que $97 \%$ das mulheres participantes consideram o curso de agropecuária machista, assim como, $62 \%$ delas já passaram por algum constrangimento ou comportamento preconceituoso por ser mulher e estar cursando ou ter cursado agropecuária. 
Através da análise dos questionários verifiquei que muitas mulheres relataram ouvir de professores e colegas, homens, que há atividades as quais não podem ser realizadas por elas, tendo como justificativa o fato de serem meninas. O argumento utilizado por eles é a necessidade da força física para o desempenho de algumas tarefas. Percebi que ainda a força física está relacionada ao gênero masculino e, consequentemente, ao curso de Agropecuária. Ailse Quadros (2017), relata que esta profissão se tornou masculinizada devido a esta relação da necessidade da força para a realização das atividades, qualidade esta que não é atribuída às mulheres. Mesmo com a mecanização e, consequentemente, o aumento do número de máquinas substituindo o trabalho do homem, a discriminação de gênero nesse setor persisti. No relato abaixo é possível reconhecer essa ideia.

[...] no segundo ano deu pra entender como esse universo 'funciona', comentários como 'não carrega isso, deixa que um guri faz', 'tu vai se machucar com tal coisa, fulano, vai lá e faz pra ela' e praticamente todos os comentários vindo dos professores [...]. (C.A. - aluna).

Em vários relatos também aparece a fragilidade feminina, característica atribuída às mulheres, como oposição à força física. Percebi que ainda é muito forte no curso a crença de que existe somente um modelo de mulher e que esta corresponde a um estereótipo antigo de fragilidade, delicadeza e cuidado. $O$ relato da aluna M.E. representa esta crença: "No curso já vi vários professores e colegas deixarem as meninas de fora de certas atividades por serem consideradas 'frágeis' [...]" (M.E. - aluna).

Esse discurso misógino produz, segundo Fernandes e Ribeiro (2018), o binarismo masculino/feminino o qual define e reforça um comportamento, modo de pensar e compreender o mundo, de acordo com o gênero da pessoa. Dos meninos se espera, socialmente, que sejam fortes e destemidos enquanto as meninas devem ser frágeis, comportadas e delicadas. Nos relatos abaixo também podemos visualizar esta ideia.

Por ser um curso das ciências rurais era muito comum encontrar um maior número de homens do que mulheres na área, desta forma nós mulheres sempre éramos vistas como delicadas, que não tínhamos capacidade de fazer o que os homens deveriam saber fazer [...] (R.Q. ex-aluna).

Também em algumas aulas do curso, os professores dividem as tarefas entre "meninas para um lado e meninos para o outro", as garotas ficando com a parte mais fácil como se fossem incapazes de realizar o mesmo que os meninos. Não sei opinar ao certo... Alguns professores se mostram sexistas ao separar as atividades por gênero ou dizer que 'Fulano agora tá fazendo trabalho de homem' como um já comentou com um colega enquanto o mesmo realizava uma prática. (U.A. aluna).

Criaram-se discursos de gênero que se perpetuam ao longo da história. Torrão Filho (2005) afirma que o discurso cultural em relação a gênero acaba por dar significados sociais de como deve ser e agir seres fisiologicamente diferentes, ou seja, homens e mulheres. A própria diferenciação entre os sexos já define as 
características identitárias esperadas para o ser masculino e feminino. Além da mulher ter que aprender a seguir o padrão feminino e submisso, também os homens são controlados e vigiados na manutenção de sua masculinidade. Isto é possível verificar na fala das alunas quando a família não as incentiva a cursarem agropecuária.

Minha própria família não queria que eu fizesse o processo seletivo para agropecuária, pois diziam que era um curso masculino, que eu não me adaptaria e preferiam que eu seguisse em outra área. (E.A. - aluna).

Em consonância com a autora Guacira Louro (2008), vejo o quanto é necessário desmistificar esta oposição entre os polos masculino e feminino. Assim como também, a emergência em aceitar a pluralidade de identidades do ser humano, ou seja, as diversas formas de masculinidade e feminilidade que pode existir. Outro ponto importante que a autora defende é a importância de acabar com a hierarquia social estabelecida entre homens e mulheres.

Percebi que ainda é muito utilizado a "maneira velada" ao negar, às mulheres, estágio ou trabalho na área da Agropecuária. A sociedade ainda tem preconceito em relação a elas no desenvolvimento das atividades rurais, apresentando desculpas na hora da contratação. Quadros (2017) chama de "violência velada" o comportamento das pessoas em não perceberem que estão sofrendo preconceito, ou até mesmo sendo preconceituosas, pois o comportamento é considerado normal naquele meio.

A autora afirma que a cultura machista faz com que as crenças fiquem naturalizadas nas pessoas levando a uma dificuldade em poder desmistificar certos conceitos, como por exemplo, ver que algumas atitudes no curso são machistas em relação às mulheres. No relato abaixo é possível visualizar uma forma disfarçada de dizer o "não":

O julgamento profissional são os mais variados: não serve para o serviço, não tem experiência, se tem experiência e já conseguiu estabelecer carreira podem julgar velha para assumir o cargo, e tantas outras maneiras veladas de dizer não. (P.A. - professora).

Todo o dia acontece alguma coisa. Hoje tenho 23 anos de profissão e consigo lidar melhor com o constrangimento. Infelizmente tive colegas extremamente competentes que desistiram. Acontece na sala de aula, com os colegas, com as chefias, com os produtores assistidos, enfim em todos os ambientes. (P.A. - professora).

Através dos relatos da professora P.A. percebi o quanto esta profissão ainda está atrelada aos homens e a dificuldade que as mulheres enfrentam nas suas rotinas diárias de trabalho. Além da professora P.A., as alunas também relatam que sofrem preconceito e constrangimento nas aulas práticas, na sala de aula e na hora de fazer estágio fora da Instituição. Os relatos a baixo apresentam esta ideia através da vivência das alunas:

[...] ademais, acredito que o maior desafio seja na busca de estágio e na inserção no mercado de trabalho posteriormente, já ouvi relatos de amigas que não puderam realizar estágio onde desejavam por motivos de não haver alojamento para mulheres, ou até mesmo porque 
determinado funcionário da empresa tem uma esposa ciumenta. No mercado de trabalho, ainda existe um grande preconceito acerca da mulher, que não tem seu trabalho visto com credibilidade e tendo que, na maioria das vezes, se sobressair de forma muito grande para conseguir um cargo em relação a um homem. (F.A. - aluna).

Ao longo dos anos no curso sofri preconceito tanto por meio de colegas como de docentes, após conclusão do curso no mercado de trabalho sofri grande preconceito em minha cidade por eu ser mulher, vi os olhares quando donos de agropecuárias olhavam meu currículo e não acreditavam em meu potencial por ser mulher, até hoje sinto dificuldade de encontrar um emprego em meu curso. (K.S. - ex-aluna).

Os dados do Censo agro - $2017^{1}$ também confirmam a crença machista dentro da profissão Agropecuária. Segundo pesquisa $81 \%$ dos estabelecimentos agropecuários são ocupados por homens, enquanto as mulheres estão em $19 \%$ destes espaços.

Em conformidade com os relatos das mulheres do curso cito Raquel Belo e Leoncio Camino (2012), os quais afirmam que mesmo sendo ofertado igualdade de oportunidades de trabalho para homens e mulheres, ainda assim existe a diferença de chances entre eles na hora de serem contratados. Isto porque a hierarquia trabalhista tem no gênero um dos primordiais componentes na criação dos perfis esperados para cada cargo. Os autores ainda citam:

O mercado de trabalho, constituindo-se como um ambiente tradutor das ideologias e representações construídas socialmente, apresenta em sua dinâmica elementos dessas realidades. Atualmente, apesar de todas as mudanças ocorridas no contexto social referentes ao preconceito contra a mulher, parece existir ainda um apego à ideologia que busca caracterizar as mulheres como menos capacitadas para determinados tipos de atividade. (BELO; CAMINO, 2012, p. 271-286)

No que se refere às famílias, sabe-se que algumas ainda possuem regras e normas sociais machistas e, a partir da educação dos filhos, transmitem e reforçam estas crenças machistas e patriarcais. Este comportamento acaba por impedir que se desnaturalize discursos preconceituosos de gênero. Em vários relatos das alunas apareceu que a família não concorda com o fato delas frequentarem o curso de agropecuária devido a esse não ser uma atividade adequada para as mulheres desempenharem:

[...] os que mais falam normalmente são os colegas, porque tem pessoas que vêm de famílias com ideias do passado que a mulher tem que ser submissa ao homem. (M.N. aluna).

Meu pai sempre cuidou de cavalos, eu sempre estive nesse meio, desde que me conheço por gente ele sempre dizia: "não te mete que isso não é coisa pra guria. (V.B. aluna).

Outro ponto importante que pode ser discutido é o fato de algumas sociedades se apresentarem mais machistas, culturalmente, do que outras. Uma ex-aluna

${ }^{1}$ https://censos.ibge.gov.br/agro/2017/templates/censo_agro/resultadosagro/produtores.html 
relatou ter frequentado o curso em duas instituições de cidades diferentes, notando a diferença no grau de preconceito em relação às mulheres na agropecuária.

Minha experiência no curso foi muito boa, eu estudei em dois campus diferentes, primeiro eu fui para o IF A, e lá convivi com muito machismo de parte de colegas, que acham que 'mulheres não podiam fazer as coisas', daí por motivo de mudança de cidade vim transferida para o IF $B$, que totalmente outra realidade, um campus que tem a mente mais aberta, ainda dá bem pra ver que tem machismo, homofobia e outras coisas, mas não é como o $A$, eu me senti mais confortável fazendo o tec em $B$, eu sentia mais respeito no campus, mesmo que ainda tenho isso de o curso ser denominado para homens e falarem que mulher é um sexo frágil. (NR - ex aluna).

Cecília Sardenberger (1994), traz que apesar da subordinação da mulher ser considerada milenar e universal, esta pode variar em modo e grau de intensidade de acordo com a época, local e classe social. Além de haver cidades com uma cultura mais machista, há também a prevalência da crença entre os idosos, pois viveram em uma época em que este discurso era mais consistente e naturalizado nas sociedades.

As crenças reproduzidas na sociedade vão passando pelas gerações e se tornando natural para as pessoas, assim, alguns comportamentos tidos hoje como negativos podem ainda ser vistos como algo normal em alguns meios sociais. Em comunidades e regiões mais tradicionais e interioranas, geralmente, este discurso tende a ser mais forte e consequentemente mais difícil a desnaturalização desses conceitos. Como se verifica no relato abaixo.

[...] muitos dos rapazes que estudam no instituto são de regiões do interior gaúcho, onde acabam crescendo em contato com uma cultura machista que vem de gerações e tendem a reproduzi-la no meio em que vivem, estudam e trabalham. (L.N. aluna).

Conforme Lima, Voig, Feijó, Camargo e Cardoso (2017) é necessário reflexões a respeito de gênero dentro das escolas e nas famílias, a fim de se buscar mudanças de crenças e desnaturalização de discursos tradicionais no que se refere a polarização e estereótipos de gênero. Estas crenças machistas, permeiam as relações e, inclusive, escolhas futuras, como a profissão a seguir. As autoras enfatizam:

Enquanto os meninos e as meninas não forem educados para a divisão de tarefas, para o respeito e a colaboração, e as escolas estiverem mais preocupadas com conteúdos, vestibular e competitividade, a equidade estará distante. Vale lembrar que cada pessoa é uma e que a busca deve ser por equidade, ou seja, por equilíbrio de oportunidades. (LIMA; VOIG; FEIJÓ; CAMARGO; CARDOSO, 2017, p. 45).

Ressalto também que intrínseco nas relações e naturalizado em nossa sociedade, além de gênero, há o de classes, raça e etnia. Isto é possível verificar na fala de uma aluna: "A gente passa por piadinhas machistas, e ainda tem que ficar quietas pelo fato de tu ser apenas uma aluna". (L.E. - aluna). Este discurso remete à condição de que ser aluna não permite que se questione, pois, culturalmente é considerado uma afronta a ordem dominante, hierárquica. 
Referente a isto, Antoniassi Almeida (2014) traz que a educação ainda é permeada por uma relação de poder, pois o professor, antigamente, era o único detentor do conhecimento e o transmitia de forma autoritária e como uma verdade absoluta. Estas relações de poder pelas quais se submetem os alunos na instituição escolar o direcionam para a obediência e como consequência formam-se indivíduos submissos e acrítico

A instituição educacional também traz resquícios de uma cultura patriarcal, conforme Débora Cordeiro (2017) há um sentimento histórico de posse na cultura das sociedades em que as mulheres são subjugadas ao seu marido. Há um romantismo em relação a esta posse e a violência passional uma vez que, na maioria das vezes, o agressor não tem antecedentes criminais e é visto como um homem trabalhador e bom pai. Esta visão deturpada e romantizada, segundo a autora, constrange e gera insegurança na hora de denunciar. Há, inclusive, a falta de confiança nas instituições públicas responsáveis, uma vez que estas também carregam vestígios de uma ideologia patriarcal. Abaixo segue o discurso da profissional que atua no NUGEDIS e caracteriza este sentimento de impunidade e da cultura de poder hierárquico dentro da Instituição Escolar:

Infelizmente, percebo que a cultura do medo e a própria vergonha impeçam que a maioria das situações seja denunciada pelas estudantes. Além disso, situações como condução inadequada, exposição da vítima e impunidade dos acusados reforçam a sensação de que "não vai dar em nada e ainda vou me prejudicar. (F.R. - profissional do NUGEDIS).

A partir da análise também percebi que dentro de uma mesma turma há alunas que acreditam haver o comportamento machista em relação a elas no curso, no entanto, outras colegas relatam não presenciarem tais atitudes. Nesse sentido, percebe-se que ocorre um processo de naturalização, pois o discurso machista é tão comum na sociedade que algumas pessoas acabam por vê-lo como algo natural. Este discurso é possível ser visto no relato da aluna: "Alguns colegas e professores geralmente não se dão por conta, mas são muito machistas" (M.N. - aluna). Tal comportamento também poder ser analisado a partir da "violência velada" como já citada anteriormente.

Monteiro, Villela, Soares (2014) relatam que o preconceito e a discriminação fazem parte de um processo social que produz desigualdade em vários quesitos sociais, como gênero, raça e sexo. O resultado deste processo é a naturalização dos comportamentos de discriminar e ser discriminado. As pessoas geralmente evitam falar de preconceito e justificam o comportamento como algo positivo e natural. Isso é possível visualizar na fala das alunas V.B. e I.A.:

Não dizendo que ele fazia isso como uma forma de machismo, mas sim porque é enraizada uma cultura de que mulher não pode fazer tal coisa porque é serviço pesado, é coisa de homem de verdade. (V.B. - aluna).

Mas dentro do campus acho que isso já é bem desconstruído porque temos as mesmas oportunidades apesar de às vezes os professores acharem nas práticas que não estamos aptas ou não temos força para realizar determinadas atividades. (I.A. - aluna). 
Continuando com a mesma ideia de naturalização, vemos que a aluna I.A. acredita que o preconceito já está desconstruído no campus, já que possuem as mesmas oportunidades que os meninos. No entanto, em um segundo momento, a mesma relata que os professores acreditam que elas não estão aptas para realizarem as tarefas propostas.

Percebi que a maioria das mulheres tem conhecimento de que há o comportamento machista na Agropecuária, reforçando assim, a urgência em propor reflexões e debates com o objetivo de derrubar crenças machistas dentro da Instituição e na sociedade em geral.

Ao concluir esta categoria constatei que o curso de Agropecuária do campus " $A$ " ainda é permeado por uma visão machista e patriarcal. Tendo em vista este comportamento percebi que ainda se faz necessário discussões, reflexões e debates em relação ao tema dentro do curso. A partir do que Louro (2008) defende, percebese a importância de as pessoas compreenderem que há diversas representações de mulheres e homens, e que é urgente a desconstrução e desnaturalização desse pensamento dicotômico e tradicional em relação à gênero.

A próxima categoria que apresentarei traz o processo de empoderamento das mulheres no curso. Existem mulheres que já percebem o preconceito existente durante e depois da formação, no entanto, elas já estão em um processo de enfrentamento e buscam a superação das barreiras existentes neste meio machista.

\subsection{Possibilidades}

Apesar do discurso machista e patriarcal, percebo que as sociedades em geral estão trabalhando na valorização das mulheres e na luta por seus direitos. Atualmente há programas sociais com o objetivo de incentivar e informar às mulheres que elas possuem o direito à uma vida livre de discriminação e violência. Outro ponto importante que vem sendo trabalhado na sociedade é a valorização e a aceitação da diversidade de gênero a partir de políticas públicas.

As políticas públicas em prol das mulheres são movimentos importantes que envolvem toda a sociedade e objetivam a contínua participação feminina em todos os espaços sociais. Ressalto a importância destes movimentos, uma vez que permitem a desnaturalização de discursos misóginos na sociedade, inclusive nas Instituições de ensino, como por exemplo, no curso de Agropecuária.

A partir da análise documental do curso de Agropecuária no campus " $A$ " visualizei um aumento significativo no número de mulheres matriculadas em um período de dez anos. Isto permitiu comprovar que elas vêm se inserindo nos espaços sociais considerados, tradicionalmente, como masculinos e enfrentando as divergências de gênero existentes. Isto é possível reconhecer no relato abaixo:

[...] aos poucos está se desconstruindo essa ideia de que a mulher não pode ser das áreas rurais. Pois antes, predominavam os homens como alunos. Hoje, tem turmas, como exemplo a minha, que tem mais mulheres ocupando o espaço. (E.L. - aluna).

Da mesma forma, percebi que há famílias as quais já superaram barreiras e desafiaram os modelos pré-estabelecidos pela sociedade, trazendo um discurso de 
direitos e valorização das mulheres. O relato a baixo mostra o quanto a família influencia na desnaturalização de discursos machistas.

Eu sempre fugi um pouco do padrão do curso de rurais, minhas bases familiares que eram minha mãe e minha irmã faziam cursos de humanas, então discussões sobre o papel da mulher na sociedade, igualdade de gênero enxergar as pessoas como pessoas independente de qualquer coisa fizeram parte da minha criação. Educação essa que levei comigo para o curso de agropecuária, onde tentava mostrar isso de forma sutil para os meus amigos e as vezes discutia um pouco mais feio a respeito com colegas mais preconceituosos que tinham um discurso carregado de preconceito. (N.C. - ex-aluna).

Esta crescente participação das mulheres na sociedade é chamada de empoderamento feminino. Mageste, Melo, Ckagnazaroff (2008) trazem que o empoderamento feminino implica na ideia de que as mulheres possam decidir sobre suas próprias vidas nos espaços públicos e privados, que tenham o direito de participar integralmente de todos os setores da economia e da sociedade. Portanto, as políticas públicas vêm ao encontro desta ideologia a qual permite as mulheres extrapolarem seu papel ditado de boa mãe e esposa.

No momento da análise constatei que o discurso machista presente no curso e na sociedade não é barreira para desmotivar algumas mulheres a seguirem na profissão. Os relatos analisados geralmente apresentam a conjunção adversativa, "mas", separando o discurso em dois momentos: barreira/enfrentamento, como é possível visualizar nos relatos abaixo:

Antes eu sentia que não era tão capaz de realizar algumas atividades quanto os meninos. Mas tive muitas experiências incríveis, e vi que nós meninas somos tão ou até mais capazes que os meninos, seja para lidar com plantas, lavoura ou animais. (E.Y. - aluna).

Nós mulheres estamos mostrando a força da mulher no agro, está sendo uma experiência muito boa, pois, não só pelo fato de eu ser mulher, mas nós sim, fizemos a diferença nesse curso. Lugar de mulher é aonde ela quiser, inclusive dentro de um curso de agropecuária, mesmo que alguns professores ou colegas discordam disso. (E.B. - aluna).

A permanência das mulheres na formação agropecuária proporciona a elas mostrar à sociedade que possuem condições para realizar as atividades definidas, culturalmente, como para homens. Este comportamento proporciona a reflexão e a desnaturalização de discursos machistas e patriarcais na sociedade. Como exemplo segue o relato da ex-aluna M.G.:

Possuímos conhecimento da técnica, do processo e de todo o contexto. É assim no meu entender que mostramos que somos capazes e somos boas naquilo que fazemos "É com ações!" e "Amando o que faz!". Nós mulheres não devemos ter medo de nada, temos que nos por de igual para igual nos respeitar, pois, só assim vamos ganhar respeito, mostrar para o que viemos, ter competência e fazer bem feito assim vamos garantir nosso espaço. (M.G. - ex aluna). 
Outro dado importante da análise é o fato de que a maioria das ex-alunas as quais contribuíram com a pesquisa estavam trabalhando na área da agropecuária ou iniciaram outro curso ligado às áreas rurais. Mageste, Melo, Ckagnazaroff (2008), afirmam que apesar das mulheres reconhecerem que não há equidade de poderes entre os gêneros nas relações de trabalho, ainda assim, elas buscam participar e estar presente nestes meios. Segundo os autores é através do reconhecimento de suas competências que elas demonstram aos demais a possibilidade de competir de igual para igual.

Também verifiquei através dos relatos que as mulheres vêm experimentando a desinstitucionalização tradicional do modelo de boa mãe, esposa e do lar. Conforme Carolina Borges (2013) as mulheres já estão reconhecendo a importância do trabalho fora do âmbito do lar para sua realização pessoal, mesmo não deixando de valorizar suas relações estabelecidas no âmbito privado. Fica evidente que para elas ter uma profissão significa sua independência financeira, realização pessoal e maior liberdade de decisões.

Atualmente no Instituto Federal Farroupilha existe o Núcleo de Gênero e Diversidade Sexual - NUGEDIS, o qual tem como objetivo desenvolver políticas e ações que objetivam promover o respeito e a valorização de todos os sujeitos a partir de debates e reflexões referente às questões de gênero e diversidade sexual.

No Núcleo de Gênero e Diversidade Sexual do campus "A", segundo a responsável, são realizadas ações em âmbito individual e coletivo. No que se refere ao atendimento individual, é feito o acolhimento da pessoa que busca ajuda, fornecese orientações e encaminhamentos conforme a situação de cada um.

Quanto ao atendimento coletivo, este é realizado a partir da divulgação, da sensibilização e formação de estudantes e servidores. Para essa demanda, em alguns momentos, convidados externos são chamados para trabalharem temas pertinentes ao objetivo do núcleo. Em outros momentos os docentes e integrantes do NUGEDIS junto aos discentes que possuem proximidade com a proposta de trabalho realizam intervenções expositivas, dialogadas e artísticas com a finalidade de discutir e refletir temas que ainda precisam ser desnaturalizados na sociedade. Além disso, segundo a profissional do NUGEDIS e o relato de algumas alunas, há no campus o projeto de ensino Café Cor o qual periodicamente aborda temáticas relacionadas ao empoderamento feminino.

Concluindo esta categoria, é possível reconhecer que houve aumento significativo no número de mulheres matriculadas no curso do campus " $A$ " em relação aos homens. Estes dados confirmam que as mulheres estão se inserindo em meios sociais tidos antigamente como "lugares de homens" e que elas vêm lutando diariamente com o objetivo de provar que gênero não é divisor de potencialidades.

\section{Considerações finais}

Concluindo este trabalho, percebi que a desigualdade de gênero é um problema antigo da sociedade e que ainda persiste em nosso meio social e educacional. Ainda há nestes espaços pessoas as quais acreditam que as mulheres são inferiores aos homens, relacionando a elas as características de fragilidade e delicadeza.

No momento da análise verifiquei que, embora o curso abrigue um número cada vez maior de mulheres, ainda apresenta uma realidade de desigualdades. Os 
estereótipos de gênero são crenças que ainda influenciam nos discursos dirigidos às mulheres no momento da prática agropecuária fora e dentro da Instituição de ensino.

A partir da análise dos questionários visualizei muitos discursos machistas e desencorajadores referente a capacidade das mulheres em realizar as atividades agropecuárias dentro e fora da Instituição. Porém, apesar desta crença persistente na sociedade foi possível reconhecer um movimento positivo em relação ao enfrentamento aos obstáculos vivenciados durante e depois da formação.

Acredito que a permanência das mulheres no curso permite a elas mostrarem à sociedade suas potencialidades nas atividades agropecuárias. Outro ponto importante que vale ressaltar é que quando elas mostram suas aptidões desmistificam a imagem histórica da mulher frágil e submissa.

As mulheres ao se fazerem presente em meios considerados historicamente para homens também possibilitam a desnaturalização da crença de que o sexo biológico define o gênero com um papel rígido e estabelecido socialmente. 0 empoderamento delas mostra para a sociedade que podem existir diversas representações de gênero e que as mulheres são livres para desempenhar o papel social que desejarem. Isto também possibilita desmistificar 0 binarismo masculino/feminino presente em nossa sociedade.

Ressalto a importância das políticas públicas em prol do empoderamento das mulheres, como as atividades realizadas no NUGEDIS, pois são trabalhos que também ajudam no processo de inserção e enfrentamento delas a este meio social machista de patriarcal. Enfatizo que a caminhada é longa, mas o progresso já é visível.

\section{REFERÊNCIAS}

ALMEIDA, Antoniassi. Relações de poder no cotidiano escolar: análise e reflexões da relação aluno-escola. Revista Educação Por Escrito. Porto Alegre, v. 5, n. 2, p. 274-285, jul./dez. 2014. Disponível em: http://dx.doi.org/10.15448/21798435.2014.2.14445. Acesso: 28 out. 2019.

ALMEIDA, Jane Soares. Mulheres, educação e religião: as interfaces do poder numa perspectiva histórica. Revista Mandágora - Gênero, Religião e Políticas

Públicas. São Paulo, v. 13, n. 13, p. 52-63, 2007. ISSN 2176-0985. Disponível em: https://www.metodista.br/revistas/revistas-

ims/index.php/MA/article/view/5554/4540 Acesso: 17 mar. 2019.

BELO, Raquel Pereira; CAMINO, Leoncio. Trabalho e Gênero: elaborações discursivas sobre os papéis profissionais. Revista Caderno de Psicologia Social do Trabalho, São Paulo, v. 15, n. 2, dez. 2012. Disponível:

http://pepsic.bvsalud.org/scielo.php?script=sci_arttext\&pid=S151637172012000200009 Acesso: 25 jun. 2020.

BRASIL. Constituição do Brasil 1988. Disponível em: www.planalto.gov.br. Acesso: nov. 2018. 
BORGES, Carolina de Campos. Mudanças nas trajetórias de vida e identidades de mulheres na contemporaneidade. Revista Psicologia em estudo, Maringá, v. 18, n. 1, p. 71-81, jan./mar. 2013. Disponível:

https://www.researchgate.net/publication/274843718_Mudancas_nas_trajetorias_d e_vida_e_identidades_de_mulheres_na_contemporaneidade/fulltext/56972e6908ae a2d74374b63e/Mudancas-nas-trajetorias-de-vida-e-identidades-de-mulheres-nacontemporaneidade.pdf Acesso: 19 jul. 2020.

COLLING, Ana Maria. Tempos diferentes, discursos iguais: a construção histórica do corpo feminino. Dourados, MS. Editora UFGD, 2015.

CORDEIRO, Débora Cristina da Silva. Por que algumas mulheres não denunciam seus agressores? Juiz de Fora, 2017. Disponível em: http://www.ufjf.br/bach/files/2016/10/DEBORA-CRISTINA-DA-SILVACORDEIRO.pdf. Acesso: 28 out. 2019.

FERNANDES, Viviane Carvalho; RIBEIRO, Vândiner. Fragilidade feminina e força masculina: o currículo dos sexos em aulas de educação física. Notandum. Ano XXI, n. 47, maio/ago. 2018 - Iji - Universidade do Porto. Disponível: https://doi.org/10.4025/notandum.47.5. Acesso: 28 out. 2019.

GIL, Antônio Carlos. Métodos e Técnicas de Pesquisa Social. 6 a edição. São Paulo. Editora Atlas, 2008.

GOMES, Gisele Ambrósio. História, mulher e gênero. Disponível em: WWW.ufjf.br/virtu/files/2011/09/historia-mulher-e-genero.pdf Acesso: 23 fev. 2019.

IBGE - Instituto Brasileiro de Geografia e Estatística. Estatística de Gênero Censo Agro 2017. Disponível em:

https://censos.ibge.gov.br/agro/2017/templates/censo_agro/resultadosagro/produt ores.html. Acesso: 15 abr. 2019.

INSTITUTO FEDERAL FARROUPILHA. Disponível em: www.iffarroupilha.edu.br. Acesso: nov. 2018.

LAUQUEUR, Thomas. Inventando o Sexo: corpo e gênero dos gregos a Freud. Rio de Janeiro. Editora Relume Dumará, 2001.

LIMA, Flaviane Izidro Alves; VOIG, Ana Elisa Gambarti; FEIJó, Marianne Ramos; CAMARGO, Mário Lázaro; CARDOSO, Hugo Ferrari. A influência da construção de papeis sociais de gênero na escolha profissional. Revista Brasileira Psicologia Educacional. Araraquara, v. 19, n.1, p. 33-50, jan./jun. 2017. Disponível: https://periodicos.fclar.unesp.br/doxa/article/download/10818/7004. Acesso: 10 jun. 2020.

LOURO, Guacira Lopes. Gênero, sexualidade e educação: uma perspectiva pósestruturalista. Petrópolis: Vozes, 2008. 
MAGESTE, Gizelle de Souza; MELO, Marlene Catarina de Oliveira Lopes;

CKAGNAZAROFF, Ivan Beck. Empoderamento de mulheres: uma proposta de análise para as organizações. IN: V ENCONTRO DE ESTUDOS ORGANIZACIONAIS (ENEO) DA ANPAD, 2008, Belo Horizonte/MG. Disponível em:

http://www.anpad.org.br/admin/pdf/EnEO548.pdf. Acesso: 10 nov. 2019.

MONTEIRO, Simone Souza; VILLELA, Wilza Vieira.; SOARES, Priscila da Silva. É inerente ao ser humano! A naturalização das hierarquias sociais frente às expressões de preconceito e discriminação na perspectiva juvenil. Revista Physis. v. 24, n.2, p.421-440, 2014. Disponível em:

http://www.scielo.br/scielo.php?script=sci_arttext\&pid=S0103-

$73312014000200421 \&$ Ing=pt\&tlng=pt. Acesso: 20 jan. 2020.

MORAES, Roque; GALIAZZI, Maria do Carmo. Análise Textual Discursiva: Processo Reconstrutivo de Múltiplas Faces. Revista Ciência \& Educação. v. 12, n. 1, p. 117-128, 2006. Disponível em: http://www.scielo.br/scielo.php?pid=S151673132006000100009\&script=sci_abstract\&tlng=pt. Acesso: 10 nov. 2019.

ONU MULHERES. Garantir os direitos humanos das mulheres no Brasil e no mundo. Disponível em: http://www.onumulheres.org.br/onu-mulheres/sobre-aonu-mulheres/. Acesso: 10 fev. 2019.

ONU BR. Nações Unidas no Brasil. Disponível em:

Https://nacoesunidas.org/?s=mulheres/. Acesso: 12 fev. 2019.

\section{QUADROS, Ailse de Cássia. A Trajetória e Desafios das Alunas do Curso} Técnico em Agropecuária Integrado ao Ensino Médio do Instituto Federal do Norte de Minas Gerais. Tese (Mestrado em Educação) - Universidade Estadual do Sudoeste da Bahia. BA, 2017. Disponível: http://www2.uesb.br/ppg/ppged/wpcontent/uploads/2017/06/Ailse-de-C\%C3\%A1ssia-Quadros.pdf. Acesso: 13 mar. 2019.

SARDENBERG, Cecília, COSTA, Ana Alice Alcântara. In: BRANDÃO, Margarida Luiza Ribeiro, BINGEMER, Maria Clara. (org). Seminários Especiais - Centro João XXIII. Mulher e relações de gênero. São Paulo. Editora Loyola, 1994.

SCOTT, Joan. Gênero: uma categoria útil de análise histórica. Revista Educação e Realidade. Porto Alegre, v. 16, n. 2, p. 5-22, jul./dez. 1990. Disponível: https://seer.ufrgs.br/index.php/educacaoerealidade/article/view/71721 Acesso: 14 jul. 2020.

SILVA, Jacilene Maria. Feminismo na atualidade: a formação da quarta onda. Independently Published. Recife, 2019. Arquivo Kindle.

SOUZA, Maria Luiza Rodrigues Sampaio. Gênero e escolha profissional. Trabalho de Conclusão de Curso. Universidade de Brasília, 2015. Disponível em: 
http://bdm.unb.br/bitstream/10483/14602/1/2015_MariaLuizaRodriguesSampaiode Souza_tcc.pdf. Acesso: 15 jan. 2019.

TORRÃO, Amílcar. Uma questão de gênero: onde o masculino e o feminino se cruzam. Cadernos Pagu - Portal de Periódicos [online]. 2005, n.24, pp.127-152. ISSN 0104-8333. Disponível em: https://doi.org/10.1590/S010483332005000100007 . Acesso: 15 jan. 2019. 